\title{
CONTROL OF SYNCHRONIZATION VIA A BACKWARD TIME CONTROLLER*
}

\author{
T. Pyragienė, K. Pyragas, A. Tamaševičius, and G. Mykolaitis \\ Semiconductor Physics Institute, A. Goštauto 11, LT-01108 Vilnius, Lithuania \\ E-mail: pyragiene@pfi.lt
}

Received 6 June 2007; revised 15 June 2007

\begin{abstract}
A weakly nonlinear self-sustained oscillator can be synchronized by an external force only in a certain domain of parameters. We exploit unstable periodic orbits and extend this domain via a small control perturbation. The controller is constructed as a backward time replica of the original oscillator that has the same periodic orbits but with the opposite stability properties. The control is achieved by synchronizing the original oscillator with its backward time replica. We demonstrate these ideas both theoretically and experimentally.
\end{abstract}

Keywords: control, synchronization, self-sustained oscillations, coupled oscillators, unstable periodic orbits

PACS: 05.45.Xt, 05.45.Gg, 02.30.Yy

\section{Introduction}

Control problems have been discussed by engineers and applied mathematicians for more than half a century $[1,2]$. However, the idea of noninvasive methods, i. e. methods where the control force vanishes when the target state is reached, has been emphasized by physicists only one and a half decade ago in the context of controlling chaos [3] and becomes one of the most rapidly developing subfields in applied nonlinear science. This subfield has boosted an enormous amount of work on control problems related to stabilization of unstable periodic orbits (UPOs) embedded in strange attractors of chaotic systems (see [4] and references therein) and leads to new concepts like external force and delayed feedback control techniques [5].

In this paper, we consider the problem of controlling synchronization in a forced self-sustained oscillator. Very often in practical application the need arises to control the properties of oscillations. Usually control assumes an enhancement in regularity of motion. Suppose that our aim is to maintain the synchronous regime of a periodically driven self-sustained oscillator. Due to drift of parameters the system may leave the synchronization domain and a kind of beat phenomenon may occur. However, outside this domain the system has unstable periodic orbits that can be stabilized by

\footnotetext{
* The report presented at the 37th Lithuanian National Physics Conference, 11-13 June 2007, Vilnius, Lithuania.
}

a small feedback perturbation, and thus the domain of synchronization can be extended with only small control force. In a recent paper [6] we have considered this problem in the framework of the delayed feedback control technique. Here we apply an external force (or proportional feedback) technique [5] to stabilize UPOs coexisting with the quasiperiodic attractor. In this technique, the control perturbation is proportional to the difference between the actual state of the system and the state corresponding to the desired UPO. An experimental implementation of this technique is usually difficult since it requires a design of a special periodic oscillator which generates a signal in the form of the desired UPO [7]. Here we show that such an oscillator can be constructed as a backward time replica of the original oscillator [8]. The backward time replica has the same periodic orbits as the original oscillator but with the opposite stability properties (i. e., unstable periodic orbits of the original oscillator coincide with stable periodic orbits of the backward time replica). Then by coupling the original oscillator with its backward time replica one can stabilize the desired UPO and extend the domain of synchronization.

The rest of the paper is organized as follows. In Section 2, we describe an analytical theory of the applied control technique and numerically demonstrate its performance for a forced van der Pol oscillator. Then the experimental implementation of the technique for an electronic self-sustained oscillator is presented. The 


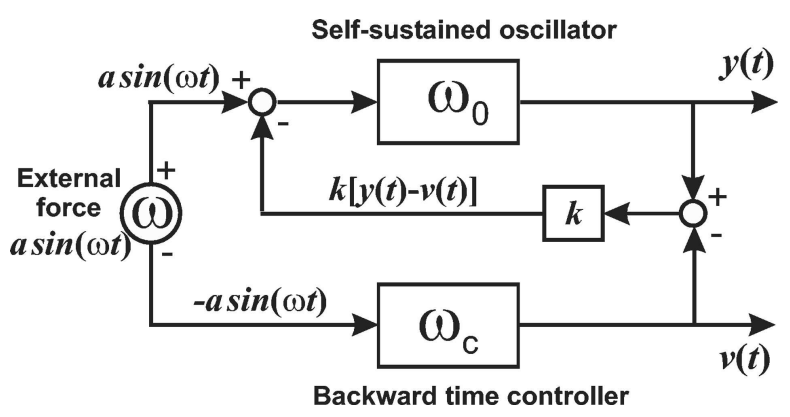

Fig. 1. Block diagram of the backward time control technique.

paper is finished with conclusions presented in Section 3.

\section{Theory of the backward time control technique}

The block diagram of the backward time control technique is presented in Fig. 1. To be specific we demonstrate its performance for a weakly nonlinear van der Pol oscillator subjected to an external periodic force. Consider the following system

$$
\begin{aligned}
& \ddot{x}+\omega_{0}^{2} x+\varepsilon\left(x^{2}-1\right) \dot{x}=a \sin (\omega t)+k(\dot{u}-\dot{x}), \\
& \ddot{u}+\omega_{\mathrm{c}}^{2} u-\varepsilon\left(u^{2}-1\right) \dot{u}=-a \sin (\omega t) .
\end{aligned}
$$

The left-hand side of Eq. (1) represents the standard van der Pol equation. The parameter $\omega_{0}$ is the characteristic frequency of self-sustained oscillations, and $\varepsilon$ is responsible for the strength of nonlinearity of the oscillator. The first term in the right-hand side is an external periodic force ( $a$ is the amplitude and $\omega$ is the frequency) and the second term describes the control perturbation. The parameter $k$ is a feedback gain. Equation (2) represents a backward time controller. This equation is derived from Eq. (1) by changing the sign of time, i. e., by the transformation $t \rightarrow-t$. The characteristic frequency $\omega_{\mathrm{c}}$ of the controller should slightly differ from the frequency $\omega_{0}$ of the original oscillator. The exact relation between these two frequencies will be presented latter.

In the following we consider Eqs. (1) and (2) as weakly nonlinear oscillators, i. e., systems that can be presented as linear oscillators with frequencies $\omega_{0}$ and $\omega_{\mathrm{c}}$ (the first two terms in Eqs. (1) and (2)) subject to small perturbations (the remaining terms in the same equations). Specifically, we suppose that the following inequalities are met:

$$
\frac{\varepsilon}{\omega_{0}} \ll 1, \quad \frac{a}{\omega_{0}^{2}} \ll 1, \quad \frac{k}{\omega_{0}} \ll 1,
$$

$$
\frac{\left|\omega-\omega_{0}\right|}{\omega_{0}} \ll 1, \quad \frac{\left|\omega-\omega_{c}\right|}{\omega_{0}} \ll 1 .
$$

For weakly nonlinear systems, there are many mathematically rigorous ways (e.g., a method of averaging, a multiscale expansion, and other asymptotic methods) to obtain approximate solutions. We will apply the method of averaging. First we rewrite Eqs. (1) and (2) in a normal form:

$\dot{x}=y$,

$\dot{y}=-\omega_{0}^{2} x-\varepsilon\left(x^{2}-1\right) y+a \sin (\omega t)+k(v-y)$,

$\dot{u}=v$,

$\dot{v}=-\omega_{\mathrm{c}}^{2} u+\varepsilon\left(u^{2}-1\right) v-a \sin (\omega t)$.

As Eqs. (4), (5) and (6), (7) are close to those of linear oscillators, we can expect that the solutions have a nearly harmonic form. Since these are forced systems, we look for solutions with the characteristic frequency $\omega$ :

$$
\begin{aligned}
& x=\frac{A(t) \mathrm{e}^{\mathrm{i} \omega t}+A^{*}(t) \mathrm{e}^{-\mathrm{i} \omega t}}{2}, \\
& u=\frac{B(t) \mathrm{e}^{\mathrm{i} \omega t}+B^{*}(t) \mathrm{e}^{-\mathrm{i} \omega t}}{2} .
\end{aligned}
$$

Here $A(t)$ and $B(t)$ are new variables, slowly varying complex amplitudes. Since they are complex, we need two relations to have one-to-one correspondence between $(x, y)$ and $A$ as well as between $(u, v)$ and $B$. It is convenient to introduce the following relations between $y$ and $A$ and between $v$ and $B$ :

$$
\begin{aligned}
& y=\mathrm{i} \omega \frac{A(t) \mathrm{e}^{\mathrm{i} \omega t}-A^{*}(t) \mathrm{e}^{-\mathrm{i} \omega t}}{2}, \\
& v=\mathrm{i} \omega \frac{B(t) \mathrm{e}^{\mathrm{i} \omega t}-B^{*}(t) \mathrm{e}^{-\mathrm{i} \omega t}}{2} .
\end{aligned}
$$

Substituting Eqs. (8)-(11) in system (4)-(7) we obtain the equations for the complex amplitudes, which after averaging over the period $T=2 \pi / \omega$ of fast oscillations take the form

$$
\begin{aligned}
\dot{A}= & \frac{\omega^{2}-\omega_{0}^{2}}{2 \mathrm{i} \omega} A-\frac{\varepsilon}{2} A\left(\frac{|A|^{2}}{4}-1\right)-\frac{a}{2 \omega} \\
& +\frac{k}{2}(B-A),
\end{aligned}
$$




$$
\dot{B}=\frac{\omega^{2}-\omega_{\mathrm{c}}^{2}}{2 \mathrm{i} \omega} B+\frac{\varepsilon}{2} B\left(\frac{|B|^{2}}{4}-1\right)+\frac{a}{2 \omega} .
$$

The second and the third terms in Eqs. (12) and (13) are equal but opposite in signs. To make the first terms equal and opposite in sign we require $\omega^{2}-\omega_{\mathrm{c}}^{2}=$ $-\left(\omega^{2}-\omega_{0}^{2}\right)$ or

$$
\omega_{\mathrm{c}}^{2}=2 \omega^{2}-\omega_{0}^{2}
$$

In a real experiment, this requirement can be kept by tuning the frequency $\omega_{\mathrm{c}}$ in such a way as to minimize the amplitude of the control perturbation $k(v-y)$. Under requirement (14), the amplitude equation (13) becomes an exact backward time copy of the amplitude equation (12) for $k=0$. Thus for $k=0$, these equations have equivalent fixed points but their eigenvalues are of opposite signs. The same is true for the periodic orbits of systems (4), (5) and (6), (7) and their Floquet exponents (FEs). Therefore, if the original oscillator (4), (5) has an UPO with positive real parts of both FEs, then the same periodic orbit, but stable, with the opposite sign of FEs, will have the backward time replica (6), (7). The stability of such orbits in the controlled ( $k \neq 0$ ) oscillator (4), (5) is defined by equation

$\dot{A}=\frac{\omega^{2}-\omega_{0}^{2}}{2 \mathrm{i} \omega} A-\frac{\varepsilon}{2} A\left(\frac{|A|^{2}}{4}-1\right)-\frac{a}{2 \omega}+\frac{k}{2}\left(A_{0}-A\right)$.

Here $A_{0}=B_{0}$ is a steady state solution of both Eq. (13) and Eq. (12), which is stable for Eq. (13) and unstable for Eq. (12) for $k=0$. Equation (15) is derived from Eq. (12) by substitution $B=B_{0}=A_{0}$, i. e., we suppose that in Eq. (13) the amplitude $B$ has reached its stable steady state, $B=B_{0}$.

By choosing an appropriate scale for the amplitude

$$
A=2 z
$$

and introducing new parameters

$$
\alpha=\frac{a}{2 \varepsilon \omega}, \nu=\frac{\omega^{2}-\omega_{0}^{2}}{\varepsilon \omega} \approx 2 \frac{\omega-\omega_{0}}{\varepsilon}, \kappa=\frac{k}{\varepsilon} .
$$

Eq. (15) can be simplified to

$$
\frac{2}{\varepsilon} \dot{z}=-\mathrm{i} \nu z-z\left(|z|^{2}-1\right)-\alpha+\kappa\left(z_{0}-z\right)
$$

where $z_{0}=A_{0} / 2$.

Now we analyse the solutions of Eq. (18). The bifurcation diagram in the plane of parameters $(\nu, \alpha)$ is shown in Fig. 2. Since it is symmetrical with respect to the $\nu$ and $\alpha$ axis, only the part $\nu \geq 0, \alpha \geq 0$ is presented. We start the analysis with finding the stationary

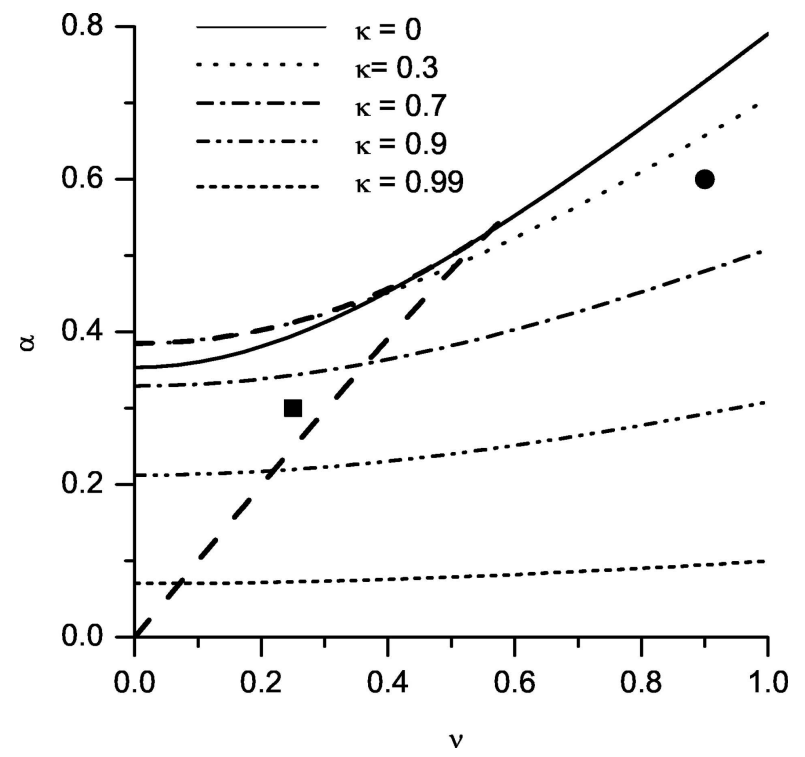

Fig. 2. The bifurcation diagram of Eq. (18). The thick dashed lines are defined by Eq. (23). The region between these lines correspond to three periodic orbits. Outside this region there is only one periodic orbit. The thick solid line is the hyperbola (26) defining the Hopf bifurcation of the uncontrolled oscillator. The broken lines represent the hyperbolas (27) for different values of the control gain $\kappa$. The solid dot $(\nu, \alpha)=(0.9,0.6)$ and square $(\nu, \alpha)=(0.25,0.3)$ show the sets of parameters which will be used in the following analysis to demonstrate the backward time control performance.

solutions of the uncontrolled system. Setting $\dot{z}=0$ and $z=z_{0}$ we obtain

$$
-\mathrm{i} \nu z_{0}-z_{0}\left(\left|z_{0}\right|^{2}-1\right)-\alpha=0 .
$$

We introduce the notations

$$
s=\left|z_{0}\right|^{2}, \quad f_{\nu}(s)=s\left[(s-1)^{2}+\nu^{2}\right] .
$$

Then the stationary values of $s$ can be found by solving the cubic equation

$$
f_{\nu}(s)=\alpha^{2}
$$

with respect to $s$. Knowing $s$, from Eq. (19) one can determine the steady state value $z_{0}=-\alpha /(s-1+\mathrm{i} \nu)$.

Solutions of the cubic equation (21) define stationary periodic orbits of the forced system. The period of these orbits is equal to the period $T$ of the external force, and the amplitude (the radius in the $(x, y)$ plane) is $\left|A_{0}\right|=2\left|z_{0}\right|=2 \sqrt{s}$. Equation (21) has three real roots provided

$$
\begin{aligned}
& \alpha_{1}^{2}(\nu)<\alpha^{2}<\alpha_{2}^{2}(\nu), \\
& \alpha_{1,2}^{2}(\nu)=\frac{2}{27}\left[9 \nu^{2}+1 \mp\left(1-3 \nu^{2}\right)^{3 / 2}\right],
\end{aligned}
$$

or one real root otherwise. Thus the forced van der Pol oscillator has either three or one periodic orbit(s). The 
region with three orbits is between thick dashed lines in Fig. 2. Outside this region there is only one periodic orbit.

To determine the stability of periodic orbits, we have to linearize Eq. (18). As a result we obtain the characteristic equation

$$
\left(\frac{2 \lambda}{\varepsilon}+\kappa\right)^{2}-2(1-2 s)\left(\frac{2 \lambda}{\varepsilon}+\kappa\right)+f_{\nu}^{\prime}(s)=0 .
$$

Here $\lambda$ is the eigenvalue of the linearized Eq. (18), which coincides with the FE of the corresponding periodic orbit, $s$ is the solution of the cubic equation (21), and

$$
f_{\nu}^{\prime}(s)=(3 s-1)(s-1)+\nu^{2}
$$

is the derivative of the function $f_{\nu}(s)$ defined in Eq. (20).

First we discuss the stability of periodic orbits of the uncontrolled system for $\kappa=0$. The stability of periodic orbit depends on the value of $s$, i. e., on the amplitude of the orbit $\left|A_{0}\right|=2 \sqrt{s}$. Two different types of bifurcations may occur in the system. For $f_{\nu}^{\prime}(s)=0$ we have a tangent (saddle-node) bifurcation, and for $s=$ $1 / 2$ a Hopf bifurcation arises. The condition $f_{\nu}^{\prime}(s)=0$ defines the boundaries $\alpha^{2}=\alpha_{1,2}^{2}(\nu)$ of the region with three periodic orbits in the $(\nu, \alpha)$ plane (dashed solid lines in Fig. 2). When crossing into this region two additional orbits of saddle and node types occur. The saddle orbit has two real FEs of different signs. Such an orbit cannot be stabilized by the backward time control technique since it remains an unstable saddle orbit for the the backward time replica. The condition of the Hopf bifurcation $s=1 / 2$ defines the minimal amplitude of the stable orbit $A_{\min }=\sqrt{2}$. The orbits with amplitude $\left|A_{0}\right|<A_{\min }$ are unstable. In the $(\nu, \alpha)$ plane, this condition defines the hyperbola

$$
\alpha^{2}=f_{\nu}(1 / 2)=\frac{\nu^{2}}{2}+\frac{1}{8},
$$

which is shown by a solid line in Fig. 2. Above this line the oscillator is synchronized with the external force. Below this curve, in the region of a single periodic solution, the synchronization is lost and we usually have a quasiperiodic behaviour.

To demonstrate the performance of the backward time controller we choose two points in the bifurcation diagram, one in the region of a single periodic orbit, $(\nu, \alpha)=(0.9,0.6)$, marked by a solid dot in Fig. 2 , and another in the region of three periodic orbits, $(\nu, \alpha)=$ $(0.25,0.3)$, marked by a solid square. For these sets of parameters, the orbits of the uncontrolled oscillator in
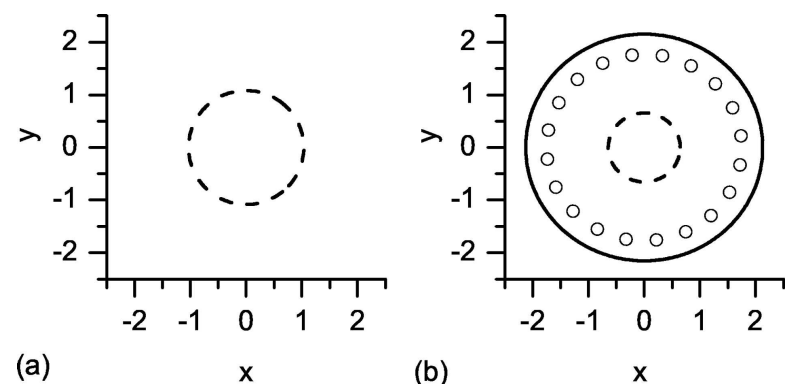

Fig. 3. Examples of periodic orbits of the forced uncontrolled oscillator. (a) The case of a single UPO corresponding to the set of parameters $(\nu, \alpha)=(0.9,0.6)$ marked by a solid dot in Fig. 2 . The amplitude of the orbit is $\left|A_{0}\right| \approx 1.034$ and its FEs $\lambda_{0} \approx$ $(0.233 \pm 0.430 i) \varepsilon$. (b) The case of three periodic orbits for $(\nu, \alpha)=$ $(0.25,0.3)$ corresponding to a solid squire in Fig. 2. The largest orbit (solid line) is stable, the middle orbit (open circles) is of a saddle type, and the smallest orbit is unstable with $\left|A_{0}\right| \approx 0.645$ and $\lambda_{0} \approx(0.396 \pm 0.114 \mathrm{i}) \varepsilon$.

the $(x, y)$ plane are shown in Fig. 3. The stable orbit is marked by a solid line. Note that it is an unstable orbit for the backward time controller. The saddle orbit is marked by open circles. It remains the saddle orbit for the controller as well. Finally, unstable orbits having a pair of complex conjugate exponents with the positive real part are marked by dashed lines. They are stable for the backward time replica. Below we consider their stabilization in the controlled original oscillator.

The FEs of the controlled oscillator satisfy Eq. (24). The condition of the Hopf bifurcation for $\kappa \neq 0$ reads $s=(1-\kappa) / 2$. Now instead of Eq. (26) we have

$$
\alpha^{2}=(1-\kappa) \frac{(1+\kappa)^{2}+4 \nu^{2}}{8} .
$$

Again this relation defines the hyperbolas in the $(\nu, \alpha)$ plane. In Fig. 2, they are shown by broken lines for different values of $\kappa$. Above these curves the corresponding orbits of the controlled oscillator are stable. It follows that for $\kappa \geq 1$ one can stabilize an UPO for any choice of the parameters $(\nu, \alpha)$. Thus the domain of synchronization of the forced self-sustained oscillator can be extended to the whole plane of parameters $(\nu, \alpha)$.

For a fixed value of parameters $(\nu, \alpha)$, the threshold of stability of a given UPO can be easily obtained from Eq. (24). Denote the FE of the uncontrolled UPO for $\kappa=0$ by $\lambda_{0}$. Then the FE of the controlled periodic orbit is $\lambda=\lambda_{0}-\kappa \varepsilon / 2=\lambda_{0}-k / 2$. For the real part of the FE we obtain

$$
\operatorname{Re} \lambda=\operatorname{Re} \lambda_{0}-\frac{k}{2} .
$$




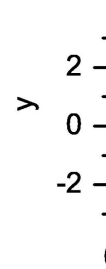

(a)
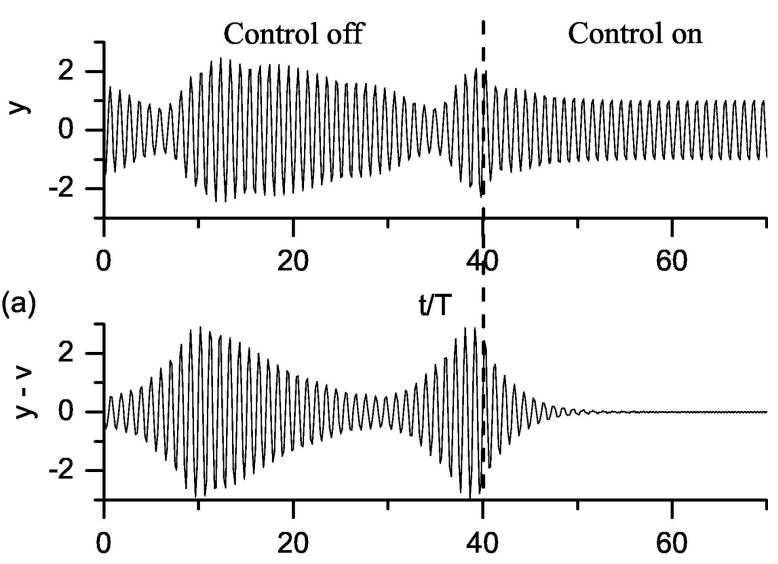

(b)

$\mathrm{t} / \mathrm{T}$

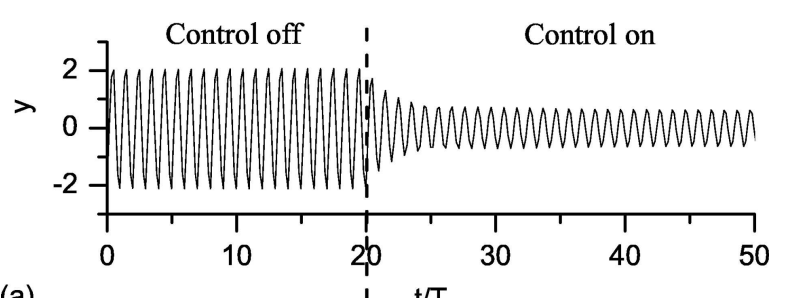

(a)

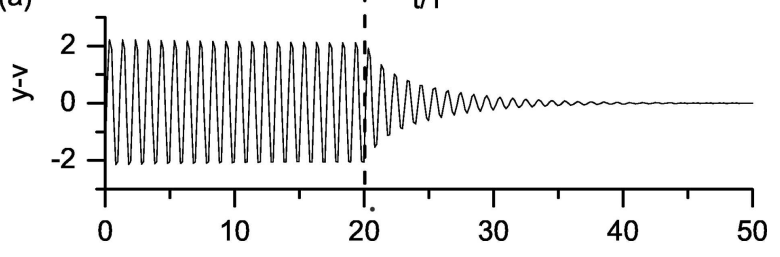

(b)

$\mathrm{t} / \mathrm{T}$

Fig. 4. Numerical simulation of Eqs. (4)-(7) for $(\nu, \alpha)=(0.9,0.6)$. The values of other parameters are $\varepsilon=0.1, \omega_{0}=1, \omega \approx 1.0460$, $\omega_{\mathrm{c}} \approx 1.1883, a \approx 0.126, k=0.15$. The control perturbation is switched on at the moment $t_{\mathrm{c}}=40 T$, i. e., $k=0$ for $t<t_{\mathrm{c}}$ and $k=0.15$ for $t>t_{\mathrm{c}}$. The backward time controller stabilizes an UPO shown in Fig. 2 (a). (a) Dynamics of the output variable $y$. (b) Dynamics of the difference $y-v$, which for $t>t_{\mathrm{c}}$ is proportional to the control perturbation.

The threshold of stability $k_{0}$ is defined by condition $\operatorname{Re} \lambda=0$, which yields

$$
k_{0}=2 \operatorname{Re} \lambda_{0}=\varepsilon(1-2 s)=\varepsilon\left(1-\frac{\left|A_{0}\right|^{2}}{A_{\min }^{2}}\right) .
$$

For $k>k_{0}$, the backward time controller stabilizes the desired UPO. Thus the synchronous regime of the forced van der Pol oscillator can be maintained with only small control force outside the domain of synchronization.

To support the above analytical theory we have performed numerical simulations of the original system (4)-(7). The results for the set of parameters $(\nu, \alpha)=(0.9,0.6)$ is shown in Fig. 4. This set corresponds to a single UPO shown in Fig. 2(a). For $\varepsilon=0.1$, the FEs of this orbit are $\lambda_{0} \approx 0.0233 \pm 0.0430$ i. It follows from Eq. (29) that the threshold of stabilization is $k_{0} \approx 0.0466$. Figure 4 shows successful stabilization of this orbit for $k=0.15$. Without control $\left(t<t_{\mathrm{c}}=40 T\right)$ the forced oscillator exhibits a beat phenomenon. The control perturbation removes the beat, and after a transient the synchronous regime with the external force is restored. The control perturbation becomes extremely small whenever the oscillator reaches a previously unstable orbit.

Figure 5 shows a control of the oscillator for the set of parameters $(\nu, \alpha)=(0.25,0.3), \varepsilon=0.1$, when the system has three periodic orbits, as presented in Fig. 2(b). The largest orbit with the amplitude $\left|A_{0}\right| \approx$ 2.12 is stable. It corresponds to the synchronized peri-

Fig. 5. Same diagrams as in Fig. 4 but for $(\nu, \alpha)=(0.25,0.3)$. The values of other parameters are $\varepsilon=0.1, \omega_{0}=1, \omega \approx 1.0126$, $\omega_{\mathrm{c}} \approx 1.0506, a \approx 0.061, k=0.15$. The control perturbation is switched on at the moment $t_{\mathrm{c}}=20 T$. The backward time controller stabilizes the smallest UPO shown in Fig. 2 (b) by dashed line.

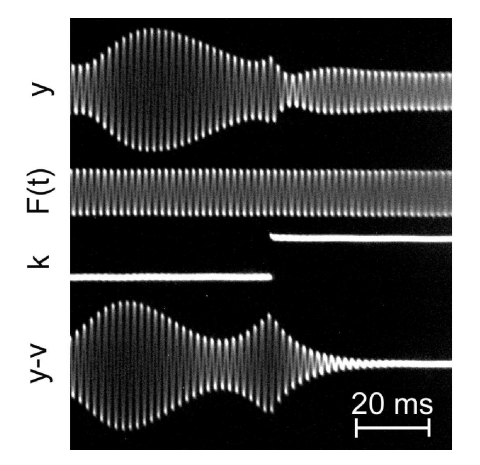

Fig. 6. Experimental results.

odic motion of the system that is observed without control for $t<t_{\mathrm{c}}=20 T$. The smallest orbit with the amplitude $\left|A_{0}\right| \approx 0.645$ is unstable; its two complex conjugate FEs are $\lambda_{0} \approx(0.0396 \pm 0.0114 \mathrm{i})$. The stabilization threshold of this orbit is $k_{0} \approx 0.0792$. The backward time controller switches the system from synchronized motion with the large amplitude to another synchronized motion with the small amplitude. When this new synchronization regime is settled the feedback perturbation almost vanishes.

Performance of the applied control technique has been demonstrated using the experimental set-up shown in Fig. 6 of Ref. [8]. The experimental results are presented in Fig. 6. They are similar to the theoretical results shown in Fig. 4. The circuit parameters are chosen in such a way that without control the self-sustained oscillator is not synchronized with an external force and beat phenomenon is observed at the output. The control signal taken from a backward time controller stabilizes an unstable periodic orbit. As a result the synchroniza- 
tion with an external force is achieved with only small control perturbation.

\section{Conclusions}

In this paper, we have applied a backward time control technique to stabilize unstable periodic orbits of a forced self-sustained oscillator close to a supercritical Hopf bifurcation. By means of this control the domain of synchronization can be extended for any values of the frequency detuning as well as the amplitude of the external force. The backward time control technique can be also used to change the synchronization regime from periodic oscillations with a large amplitude to periodic oscillations with a small amplitude. The control is achieved by using only a small feedback perturbation.

The analytical theory of the backward time control is presented for a specific problem of a forced van der Pol oscillator. We have obtained simple analytical expressions for the dependence of the Floquet exponents on the control gain and determined the threshold value of stability. The analytical approach is based on the averaging method, a classical method of the nonlinear dynamics developed for weakly nonlinear oscillators, and can be applied for any forced self-sustained oscillator close to the Hopf bifurcation. Thus the main results are suitable for a wide class of dynamical systems.

We have demonstrated experimentally the efficiency of the backward time control technique for an electronic circuit. A good agreement with the theoretical results has been obtained. The fact that the method works in a real experiment confirms its robustness against noise and small mismatch of the parameters in the controller and controlled system.

We have recently considered [6] the problem of controlling a forced self-sustained oscillator in the framework of the delayed feedback control technique. The main differences between the delayed feedback and the backward time control approaches are as follows. The delayed feedback control is reference-free; it does not require the knowledge of the model of the controlled system. In the ideal case, the feedback perturbation vanishes when the desired synchronous state is reached. In contrast, in the backward time control technique we need a knowledge of the model equations when designing the backward time replica of the system. Here the control perturbation vanishes only in a quasiharmonic approximation (for averaged equations), but is not exactly equal to zero (although it is extremely small) for the original nonlinear system. How- ever, the backward time control has some advantages. It is more efficient than the the delayed feedback control. Here the Floquet exponents of the controlled orbits decrease linearly with the increase of the control gain and can reach arbitrarily large negative values, while in the delayed feedback the stabilization is possible only in a certain interval of the control gain and the Floquet exponents cannot take large negative values. Thus in the backward time control the system approaches the desired synchronous state mach more faster than in the delayed feedback (compare Fig. 4 of this paper with Fig. 10 of Ref. [6]).

\section{References}

[1] H. Nijmeijer and A. Schaft, Nonlinear Dynamical Control Systems (Springer, New York, 1996).

[2] K. Ogata, Modern Control Engineering (Prentice-Hall, New York, 1997).

[3] E. Ott, C. Gregory, and J.A. Yorke, Controlling chaos, Phys. Rev. Lett. 64, 1196-1199 (1990).

[4] Handbook of Chaos Control, ed. H.G. Shuster (WilleyVCH, Weiheim, 1999).

[5] K. Pyragas, Continuous control of chaos by selfcontrolling feedback, Phys. Lett. A 170, 421-428 (1992).

[6] T. Pyragienė and K. Pyragas, Delayed feedback control of forced self-sustained oscillations, Phys. Rev. E 72, 026203-1-9 (2005).

[7] A. Kittel, K. Pyragas, and R. Richter, Prerecorded history of a system as an experimental tool to control chaos, Phys. Rev. E 50, 262-268 (1994).

[8] K. Pyragas, T. Pyragienè, A. Tamaševičius, and G. Mykolaitis, Control of forced self-sustained oscillations via a backward time controller, Phys. Lett. A 350, 349-354 (2006). 


\title{
SINCHRONIZACIJOS VALDYMAS APGRĘ̌̌TO LAIKO VALDIKLIU
}

\author{
T. Pyragienè, K. Pyragas, A. Tamaševičius, G. Mykolaitis
}

Puslaidininkiu fizikos institutas, Vilnius, Lietuva

\section{Santrauka}

Neinvazinio valdymo ideja buvo suformuluota [3] darbe, kuris davė pradžią naujai mokslo krypčiai - chaoso valdymui. Buvo atkreiptas demesys $i$ tai, kad chaotinis atraktorius yra sudarytas iš begalinès aibès nestabilių periodinių orbitų. Jas galima stabilizuoti nykstamai maža grįžtamojo ryšio jèga, ir tuo pačiu chaotini sistemos judejimą paversti periodiniu. Neseniai nestabilių periodinių orbitu stabilizacijos ideja buvo apibendrinta kvaziperiodinėms sistemoms. Pasirodo, kad kvaziperiodiniam judejjimui taip pat yra būdingos nestabilios periodinès orbitos. Kai neautonominis savaiminiu virpesių osciliatorius yra mūšos režime, galima stabilizuoti jo nestabilias periodines orbitas ir tuo pačiu neinvaziškai praplèsti sinchronizacijos ribas. Tam buvo pritaikytas žinomas uždelstojo grižtamojo ryšio metodas [6].

Siekiant greičiau grąžinti sistemą i sinchronizacijos režimą, kitaip negu uždelstojo grižtamojo ryšio metodo atveju, mes pasiūlème naują neinvazinio valdymo algoritmą. Šio metodo idèja remiasi pagalbinio osciliatoriaus, kurio lygtys sutampa su pirmojo osciliatoriaus lygtimis, tik laiko ženklas yra priešingas, konstravimu. Sinchronizuojant pirmaji osciliatorių su pagalbiniu, galima stabilizuoti jo nestabilią periodinę orbitą ir taip priversti ji sinchronizuotis su išorine periodine jèga. 